\title{
Audacia, saxa pyramidum
}

Keywords: máster; derecho animal

\author{
DISCURSO CLAUSURA MÁSTER 1ª ED, (JUNIO 2012)
}

\section{Autoridades Académicas, Autoridades de la administración, estimados Alumnos del Master, Sras. y} Sres.

El acto de clausura de la parte presencial de la $1^{\text {a }}$ edición del Master en Derecho Animal y Sociedad, se desarrollará de la siguiente forma:

En primer lugar introduciré a la persona de nuestro Conferenciante de hoy, el Prof. Steven Wise Una vez finalizada la conferencia, daré la palabra a una representación de los alumnos del Máster: Alexandra Leitold y Juan Ignacio Serra [1] y a una representación de los Profesores, en la persona de nuestra colega y estrecha colaboradora, la Dra. Marta Tafalla

Por último, se clausurará esta sesión y se invitará a los presentes a una pequeña celebración

Es un placer y un honor dar la bienvenida en esta Facultad de Derecho al Prof. Steven Wise.

El Prof. Wise ya nos ha honrado con su presencia en otras dos ocasiones, lo que muestra su generosidad intelectual y su compromiso en apoyo del Master.

Glosar la personalidad del Prof. Wise en pocas palabras es vano intento. Por lo que me limitaré a destacar que destaca especialmente en tres aspectos de su trabajo:

-es un brillante escritor, de libros como Rattling the Cage” que han superado cifras de ventas en todo el mundo;

-es un excelente abogado en pro de los animales; de ahí ha extraído una gran experiencia en un campo muy necesario para el crecimiento del Derecho Animal, que es la relación con los jueces y el estudio del lenguaje de los jueces;

-es un profesor muy apreciado en las más importantes Universidades norteamericanas. Fue pionero de la enseñanza del Derecho Animal en la Universidad de Harvard en 1991. Desde entonces su labor ha sido incansable a favor de los animales, poniendo al servicio de estos lo mejor de sus capacidades y logrando que, muchos hayamos podido aprender que, el mejor favor que hoy en día podemos hacer por los animales, es trabajar profesionalmente por ellos y formarnos de manera excelente.

Gracias Steve por tu entusiasmo con la labor que este Máster ha asumido!

\section{PALABRAS DE CLAUSURA}

Me corresponde ahora el turno de cerrar este acto y no quiero dejar pasar la ocasión de exteriorizar mi agradecimiento.

Muy especialmente a todos quienes lo han hecho posible, que son, por este orden Alumnos y Profesores. Cada uno ha dado lo mejor de sí mismo y ha tratado de reproducir ese ambiente, tan propio de la Universidad, que es promover entre unos y otros una "forma superior de convivencia culta" (usando las palabras de mi Maestro). Sí, se ha discutido, se ha preguntado, se han abierto puertas a nuevos intereses, 
se ha convivido y se han ido limando esas aristas que, a veces, afloran en todo grupo con un interés apasionado por algo y todo ello en medio de un ambiente grato, abierto y tolerante. Como es propio de la sede en la que nos encontramos.

También quiero mencionar a quienes no aparecen pero hacen posible que todo funcione. Entre ellos, muy especialmente a Carlos Contreras, nuestro Coordinador de Estudiantes. Merece toda nuestra admiración por su inteligente, callada y eficaz labor, sin perder nunca la sonrisa. A todo el personal tanto de la Escuela de Postgrado como de nuestra Facultad, que nos han atendido en todo momento sin reservas. Aquí muy especialmente a Teresa Armengol y Annamaría García, de la EP y a Lluïsa Romero y Gervasio García de nuestro Departamento.

Un Máster cómo éste es un conjunto de piezas individuales que dan el todo. A esa voluntad de construir se debe que hoy estemos aquí.

Cuando comencé a dar vueltas a la idea de cómo empezar, me vino a la cabeza un fragmento de un texto de Horacio que me sigue pareciendo inspirador: “audacia, saxa pyramidum”. Es decir, la audacia es la piedra de la que están hechas las pirámides.

Os dejo esta reflexión, porque sólo este es nuestro mérito: que todos los que estamos aquí hemos tenido la audacia de creer y apostar por esta idea, por este Máster.

Gracias de todo corazón! 